\title{
Vaginal or Caesarean Delivery? A Comparative Study of Factors Associated with the Choice Method of Childbirth Delivery in Kenya and Egypt
}

\author{
Gilbert Omedi, Margaret Mwaila and Sarafina Wanja
}

\section{ABSTRACT}

Background: Childbirth delivery today is becoming a complex process. There exist linkages between choice method of childbirth delivery, whether vaginal or caesarean section, and socioeconomic, maternal, and pregnancyrelated factors.

Study objectives: To compare the choice method of childbirth delivery among women of childbearing ages in Kenya and Egypt. Specifically, the study sought to (a) show patterns of caesarean section births in the two countries using women's background characteristics, (b) estimate levels and differentials of caesarean births in the two countries and, (c) investigate the socio-economic, maternal and pregnancy-related factors that determine the choice of caesarean section deliveries in the two countries

Data and methods: Data was derived from the 2014 Kenya and Egypt demographic and health surveys women-file. The data was fitted in the Statistical Package for Social Sciences in which descriptive and binary logistic regression analyses were conducted.

Results: Majority of Egyptian women $(53.5 \%)$ gave birth by caesarean section compared to Kenyan women $(\mathbf{7 . 8 \%})$. At descriptive analysis level, all the study variables were significant at $\rho<0.05$ and less, save for marital status. At inferential level, there were higher odds of caesarean section delivery among Egyptian women in middle and rich households (1.318 and 1.701, respectively) compared to those from poor households. Among Kenyan women, those aged 25-34 and $35-49$ were 1.335 and 1.690 more likely to delivery by caesarean section compared to their colleagues in the 15-24 age group. Pertaining to the number of antenatal care visits, Egyptian women who had no antenatal care visits were 0.761 less likely, while those with 5-8 and at least 9 antenatal care visits were 1.296 and 1.783 , respectively, more likely to delivery by caesarean section compared to their colleagues with 3-4 antenatal care visits. Such a trend was observed among Kenyan women for 5-8 and 9+ antenatal care visits, at the odds of 1.234 and 2.053 respectively. Childbirth deliveries in private health facilities had the odds of 2.060 and 1.438 in Egypt and Kenya, respectively, compared to delivery in public health facilities.

Conclusion: The results suggest that the main contributory factors behind the choice method of childbirth delivery are household wealth (Egypt), maternal age (Kenya), number of antenatal care visits (both Kenya and Egypt), and place of delivery (both Kenya and Egypt).

Keywords: Type of childbirth, Place of delivery, ANC visits, Egypt, Kenya, 2014 Egypt Demographic and Health Survey, 2014 Kenya Demographic and Health Survey.

\section{INTRODUCTION}

When a pregnancy gets to term, every woman finds a reason to put a smile on her face, having persevered a long gestation period. Yes, childbirth can be a painful process for some, but the pain is short-lived when new mothers hear the first cry of their babies.
Published Online: December 4, 2020

ISSN: $2593-8339$

DOI: $10.24018 /$ ejmed.2020.2.6.579

\section{Gilbert Omedi}

Kaimosi Friends University College, Kenya.

Margaret Mwaila

National Council for Population and Development, Kenya.

(e-mail: mmwaila@yahoo.com) Sarafina Wanja

Social Researcher and Monitoring and Evaluation Specialist, Kenya.

*Corresponding Author
Every woman undergoes a unique experience at childbirth especially based on the choice method of delivery. Technology has availed alternative methods that can reduce the intensity of childbirth pain for women who find themselves in precarious situations during delivery. Childbirth delivery can be either vaginal or caesarean section. How a woman comes to know about vaginal or 
caesarean section birth is a continuous process that begins before pregnancy and continues way after a woman's first experience of childbirth. Women's views and decisions on childbirth delivery method are informed by accessing different kinds of knowledge (medical, non-medical, written, verbal, visual) from multiple sources (family, friends, media, healthcare professionals), with varying degree of influence at different time-points [10]. Nearly 45 percent of women knew what type of birth (vaginal/caesarean section) they wanted before they became pregnant, with the choice method reflecting a desire to avoid more invasive options such as use of epidural and oxytocin, preferred place of birth and type of care provider [19]. The analytical findings of the study revealed four major categories of information that were used to inform birthing choices: stories about birth and/or attending a birth, childbirth classes, healthcare providers and written sources such as childbirth books, medical journals and online services. Before making a choice of childbirth delivery method, it is important for a mother to be taken through risks and benefits of available childbirth delivery method, which must be weighed along her preference to determine what is right for her.

According to a recent medical review, infants born vaginally tend to have fewer respiratory problems, and mothers tend to recover faster, while avoiding abdominal surgery and the associated risks that come with a caesarean section [17]. Besides, vaginal birth has a lower rate of infection and a shorter hospital stay. However, a vaginal birth may encounter the tearing of the perineum and sometimes may not be recommended for medical reasons. Since vaginal delivery may not always be possible, caesarean section delivery may be necessary for the safety of the mother and the baby. This is especially if the baby is not in the head-down position, or it is too large to pass through the pelvis of the mother, or is in distress. Again, cases of ante-partum haemorrhage, prolonged and obstructed labour, placenta previa and other life threatening medical indications call for emergency surgery.

A caesarean section involves a horizontal incision across the lower abdomen through which the infant is delivered. It is an obstetric surgical procedure meant to save the life of a mother and her baby [1]. A full recovery after a caesarean section can take a period of eight weeks. Naturally, an actual childbirth method would be determined by the circumstance of a pregnancy, the position of the baby, the child-labour course, and the practices of the midwives and obstetricians encountered during pregnancy and childbirth.

A number of studies on choice method of childbirth delivery [2], [10], [13], [14], [19] have been conducted. However, few exist on a comparative basis. This was a cross-sectional retrospective study that aimed at identifying factors associated with the choice method of childbirth delivery among women of child bearing ages in Kenya and Egypt using 2014 Kenya and Egypt demographic and health surveys data. This is at the backdrop of the fact that actual childbirth by caesarean option was reported at 52 percent and 8 percent in Egypt and Kenya, respectively. According to a report by World Health Organisation [25], the ideal rate for caesarean sections is considered to be between 10 percent and 15 percent, a position that has been held by the international healthcare community since 1985 . There has not been research evidence indicating benefits of caesarean section delivery for women or infants who do not require the procedure. While Kenya is within the recommended proportion of caesarean births, Egypt's proportion is more than three times higher. The disparity between the two countries is quite wide. Given that both countries were ranked in the low mid-income economic band according to the World Bank ranking, it is important to understand the drivers for caesarean section deliveries in Kenya and Egypt on a comparative basis. Besides contributing to academic literature, the study findings are important in guiding both perinatal and prenatal counselling services.

\section{StUdy OBJECTIVES}

The overall objective of this study was to compare the choice method of childbirth delivery in Egypt and Kenya by analysing data from the 2014 demographic and health surveys of the two countries. Specifically, the study sought to:

a. Show patterns of caesarean section births in the two countries using women's background characteristics,

b. b. Estimate levels and differentials of caesarean births in the two countries, and

c. c. Investigate the socio-economic, maternal and pregnancy-related factors that determine the choice of caesarean section deliveries in the two countries.

\section{REVIEW OF LITERATURE}

Childbirth delivery method can be either vaginal or caesarean section. Various factors have been documented to explain the method-choice of childbirth delivery. In their study titled "Caesarean delivery and associated socioeconomic factors and neonatal survival outcomes in Kenya and Tanzania using national survey data", [1] found caesarean section delivery rates to range from 5 percent among uneducated, rural Tanzanian women to 26 percent among educated urban women in Kenya to 37.5 percent among managers in urban Tanzania. There were higher odds of caesarean delivery among mothers from richest households, aOR 1.4 (95\% CI 1.2-1.8), those insured, aOR 1.6 (95\% CI 1.3-1.9) highly educated, aOR 1.6 (95\% CI 1.2-2.0) and managers, aOR 1.7 (95\% CI 1.3-2.2), compared to middle class, no insurance, primary education and unemployed, respectively.

Childbirth delivery can take place at home, en-route to health facility or in a health facility. Hospital delivery has such benefits as ready access to emergency interventions such as caesarean section, advanced monitoring for highrisk pregnancies, and better pain-management options including epidural anaesthesia. However, a hospital delivery might be characterised by a higher chance of unwanted intervention, a higher chance of infection, and sometimes the hospital setting can lead to rushing through the child labour stages resulting in a higher chance of incision of the perineum during child birth, and requiring a caesarean.

Home delivery is perceived to be a safe and relaxing natural childbirth delivery method for women with a 
normal, low-risk pregnancy. In such deliveries, a variety of mind-body techniques and preparation methods are employed to reduce childbirth pain and promote an easy labour and delivery. Besides being a relaxing and comforting process, some women prefer home deliveries because of less worry about being transported to the hospital while in labour or home after childbirth, easy recovery and transition to breastfeeding in a familiar environment. At home, a mother has freedom to invite whomever she wants to attend the birth as well as to yell and vocalise during the child birth process. A home delivery might have the demerits of requiring transport to a hospital in case the birth plan progresses abnormally and not being a good option unless it is a low-risk pregnancy and the mother prefers it.

A study done in Dega Damot District of North West Ethiopia found that 38.2 percent of women had delivered in health facilities while 61.8 percent delivered at home for their most recent births. The main reasons cited for delivery in health facilities included fear of complications, to get better services, safe and clean delivery, and that they were encouraged to deliver at health facilities during antenatal care attendance [2]. The study noted that the behaviour and attitudes of healthcare providers were important factors for choice of place of delivery. The study found that some health workers were impolite, with offensive language and unsupportive, attitudes that inhibit women to deliver in health facilities. In agreement with other studies such as [4], the study found educational status of women to be the most significant factor influencing place of delivery. Women with some secondary education were more likely to utilise health facility delivery care services compared with those with no education. The authors explained that a higher level of female education in the community leads to better awareness of the need for care during childbirths and female autonomy to utilise health facility services.

A study conducted on non-pregnant women who had never had a prior birth showed that majority of women (92 percent) preferred vaginal delivery to a caesarean section delivery. To them, vaginal delivery was the normal/natural way to go/the way that it is meant to happen, and that they had a desire to avoid surgery and the longer recovery time associated with caesarean section. Few were however, influenced by friends and families who had delivered vaginally. The 8 percent who would elect to have a caesarean section cited first-hand experiences as a factor in their decision making whereby they and their siblings were delivered by caesarean section, and that vaginal delivery was scaring compared to Caesarean section that was lessstressful, less-embarrassing and simpler [13]. In their study on 'Decision making about mode of delivery among pregnant women who have previously had a caesarean section', [14] found that women were influenced by their own previous experiences and expectations. In such cases, the final decision on mode of childbirth delivery often developed during the course of the pregnancy. Most women acknowledged that any decision was provisional and might change if circumstances necessitated. The study concluded that women who have had a previous caesarean section do not usually have firm ideas about the mode of childbirth delivery. Some women look for targeted information and guidance from medical personnel based on their individual circumstances, and some are unhappy with the responsibility of deciding how to deliver in the current pregnancy.

In their case-control study on "Factors associated with caesarean sections among mothers delivering at Mama Lucy Kibaki Hospital, Nairobi, Kenya between January and March, 2015", [9] found that, of the 65.4 percent emergency caesarean sections, 25 percent were due to failure of labour to progress. Of the elective caesarean sections, 19.7 percent were repeat caesarean section. Delivering a baby with a normal birth weight $(\mathrm{cOR}=0.39$ $(95 \%$ CI $0.18,0.94))$ and being formally employed (cOR = $1.90(95 \%$ CI 1.4, 3.1)) were associated with a caesarean section. Being formally employed $(\mathrm{aOR}=1.78, \mathrm{p}=0.030)$ was independently associated with a mother undergoing a caesarean section compared to mothers who were not formally employed, while mothers whose babies had a normal birth weight, $\geq 2.5 \mathrm{~kg}(\mathrm{aOR}=0.40, \mathrm{p}=0.040)$ were less likely to undergo a caesarean section compared with mothers whose babies had a low birth weight. Many low birth weight babies were likely to be premature and of cephalo-pelvic disproportional mothers [15], [16] thus calling for a caesarean section delivery.

Several studies have revealed that the uptake of antenatal care services is a strong determinant of utilisation of institutional delivery [2], [23], places where the option for a caesarean section exist. The advice received from the healthcare workers during antenatal care visits increases the women's use of institutional delivery in that the healthcare workers could provide good information regarding safe healthcare delivery and encourage women to deliver at health facilities. Optimizing antenatal care visits could work towards preventing the excess risk of low birth weight, premature deliveries and perinatal mortality [18], all of which are likely to result in delivery through a caesarean section. Arresting the factors associated with caesarean section deliveries called for the county department of health to promote focussed antenatal care as this would help to identify pre-existing health conditions and detect early complications during pregnancy [9].

\section{DATA AND METHODS}

\section{A. Data Sources}

This comparative study used cross-sectional data derived from the Egypt and Kenya Demographic and Health Surveys (DHS) of 2014.

\section{B. Variables}

The outcome variable was choice method of childbirth delivery which was dichotomised as either vaginal or caesarean section. Further, the dependent variable was subjected to filters to obtain information from women (1549) who reported having their last birth during the five years prior to the survey.

The socio-economic variables based on the reviewed associations with the choice method of childbirth delivery were: type of place of residence - categorised as either urban or rural; maternal education - categorised as no 
education, primary education and secondary and higher education; wealth index - categorised as poor, middle/ average or rich, and maternal occupation - categorised as not working, professional, self-employed/agriculture and domestic service/manual work.

The maternal and pregnancy-related variables were: maternal age - categorised as 15-24, 25-34 and 35-49; marital status - categorised as either single (single/divorced/widowed/separated) or married; uptake of antenatal care (ANC) services - categorised as 0, 1-2 3-4, 58 and 9 or more and place of delivery - categorised as home, public health facility, private health facility and other.

\section{Data Analyses}

Analyses were done at three levels. At level one, the Student's T-Distribution was used to test the hypothesis that the two data sets of Egypt and Kenya were comparable. The distribution plays a role in a number of widely used statistical analyses including student's t-test for assessing the statistical significance of the difference between two sample means, the construction of confidence intervals for the difference between two population means, and in linear regression analysis. Such a distribution is used when the study sample size is small or when one does not know the population standard deviation, a scenario that is nearly always the case in the real world [6,22]. The t-test is conducted as follows:

$$
\mathrm{t}=(\overline{\mathrm{x}}-\mu) / \mathrm{s} / \sqrt{\mathrm{n}}
$$

where:

$\overline{\mathrm{x}}=$ sample mean.

$\mu=$ population mean.

$\mathrm{s} / \sqrt{\mathrm{n}}=$ standard error $(\mathrm{SE})$.

Thus,

$$
\mathrm{t}=(\overline{\mathrm{x}}-\mu) / \mathrm{SE}
$$

Analytical software (Statistical Package for Social Sciences (SPSS) version 22) was applied at descriptive and advanced levels. At descriptive level, Pearson's chi-square test was used to examine the proportional distribution of the study variables based on the choice method of child delivery. Binary logistic regression analysis was conducted at inferential level to assess the association between the study variables and the choice method of child delivery. The multiple binary logistic regression equation is:

$$
\begin{gathered}
\mathrm{P}(\mathrm{Y})=\exp \left(\beta_{0}+\beta_{1} \mathrm{X}_{1}+\beta_{2} \mathrm{X}_{2} \ldots+\beta_{\mathrm{n}} \mathrm{X}_{\mathrm{n}}\right) /\left(1+\exp \left(\beta_{0}+\beta_{1} \mathrm{X}_{1}+\right.\right. \\
\left.\beta_{2} \mathrm{X}_{2} \ldots+\beta_{\mathrm{n}} \mathrm{X}_{\mathrm{n}}\right)
\end{gathered}
$$

where:

$\mathrm{P}=$ Probability of a success.

$\mathrm{Y}=$ Dependent variable.

$\beta_{0}=$ Constant

$\beta_{\mathrm{n}}=$ Coefficients of variables $\mathrm{X}_{1} \ldots \mathrm{X}_{\mathrm{n}}$.

$\mathrm{X}_{\mathrm{n}}=$ Independent variables $\mathrm{X}_{1} \ldots \mathrm{X}_{\mathrm{n}}$.

The model predicts the probability of an event (Y) occurring when coefficients Beta and $\mathrm{X}$ variables are fitted on the binary regression model.

\section{FINDINGS}

This section discusses results of the descriptive and binary logistic regression analyses. The descriptive analysis comprised of the Student's T-Test, cross tabulations and chi-square tests conducted on background characteristics and covariates of method of childbirth delivery. In the multiple binary logistic regression model, the dependent variable (last birth was caesarean) was fitted against all the predictor variables.

\section{A. Results of the Student's T-Distribution}

The study datasets were fitted in the Student's TDistribution equation to ascertain their comparability at a 95\% confidence level. The computations and their respective results were as indicated in Table 1.

TABLE 1: RESULTS OF THE STUDENT'S T-DISTRIBUTION TO ASCERTAIN THE COMPARABILITY OF THE 2014 KDHS AND 2014 EDHS DATA

\begin{tabular}{ccccc}
\multicolumn{5}{c}{ THE COMPARABILITY OF THE 2014 KDHS AND 2014 EDHS DATA } \\
\hline $\begin{array}{c}\text { Age } \\
\text { group }\end{array}$ & $\begin{array}{c}\text { Kenya } \\
(\mathbf{x})\end{array}$ & $\begin{array}{c}\text { Egypt } \\
(\mathbf{y})\end{array}$ & $|\mathbf{x}-\mathbf{y}|$ & $(\mathbf{x}-\mathbf{y})^{\mathbf{2}}$ \\
\hline $\mathbf{1 5 - 1 9}$ & 6078 & 738 & 5340 & 28515600 \\
$\mathbf{2 0 - 2 4}$ & 5405 & 3051 & 2354 & 5541316 \\
$\mathbf{2 5 - 2 9}$ & 5939 & 4718 & 1221 & 1490841 \\
$\mathbf{3 0 - 3 4}$ & 4452 & 4133 & 319 & 101761 \\
$\mathbf{3 5 - 3 9}$ & 3868 & 3473 & 395 & 156025 \\
$\mathbf{4 0 - 4 4}$ & 2986 & 2902 & 84 & 7056 \\
$\mathbf{4 5 - 4 9}$ & 2351 & 2747 & 396 & 156816 \\
Total & $\mathbf{3 1 0 7 9}$ & $\mathbf{2 1 7 6 2}$ & $\mathbf{1 0 1 0 9}(\mathbf{X})$ & $\mathbf{3 5 9 6 9 4 1 5}\left(\mathbf{X}^{\mathbf{2}}\right)$ \\
\hline
\end{tabular}

$\mathrm{H}_{0}=$ population difference $=0$

$\mathrm{H}_{1}=$ population difference $\neq 0$

$\mathrm{n}=7$

$\mathrm{df}=\mathrm{n}-1=7-1=6$

Applying the student's t-distribution equation to compute the sample population difference:

$$
\begin{aligned}
& \mathrm{t}=(\overline{\mathrm{x}}-\mu) / \mathrm{SE} \\
& \bar{X}=10109 / 7=1444.143 \\
& X^{2}=35969415 \\
& \mathrm{~S}^{2}=\left\{\mathrm{x}^{2}-(\mathrm{x})^{2} / \mathrm{n}\right\} \div(\mathrm{n}-1)=(35,969,415-14,598,840.14) \div \\
& (7-1)=3,561,762.476
\end{aligned}
$$

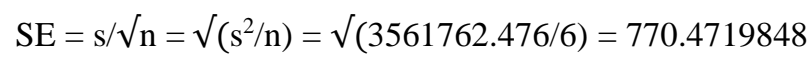

$$
\begin{aligned}
& \mathrm{t}_{\text {calculated }}=(\overline{\mathrm{x}}-\mu) / \mathrm{SE} \quad\left(\text { for } \mathrm{H}_{0}, \mu=0\right) \\
& =(1444.143-0) / 770.4719848=1.874 \\
& \mathrm{t}_{\text {critical }}=1.943(\text { at } \alpha=0.05, \mathrm{df}=6)
\end{aligned}
$$

Thus. the calculated t-distribution is accepted.

Save for the 45-49 age group, Kenya had majority of the respondents in all other age groups compared to their colleague nation, Egypt. The respondents' sample mean was 1444.143, the population mean zero for the null hypothesis, and the standard error was found to be 770.4719848. The calculated t-distribution value was 1.874 . For the range of one-sided critical region, at 6 degree of freedom and $95 \%$ confidence level, the tabulated critical tdistribution value was 1.943 . With the calculated t-value being less than the critical t-value, then we accepted the null 
hypothesis that the study populations' mean difference is zero and thus the two datasets can be used for comparative analyses.

\section{B. Background Characteristics}

TABLE 2: BACKGROUND CHARACTERISTICS OF WOMEN WHO REPORTED HAVING A LAST BIRTH WITHIN THE FIVE YEARS PRIOR TO THE STUDY IN

\begin{tabular}{|c|c|c|c|c|}
\hline \multirow{2}{*}{$\begin{array}{c}\text { Variables } \\
\text { Place of residence }\end{array}$} & \multicolumn{2}{|c|}{ EGYPT } & \multicolumn{2}{|c|}{ KENYA } \\
\hline & Count & $\%$ & Count & $\%$ \\
\hline Urban & 4769 & 41.5 & 5164 & 34.5 \\
\hline Rural & 6726 & 58.5 & 9785 & 65.5 \\
\hline \multicolumn{5}{|c|}{ Education attainment } \\
\hline No Education & 1930 & 16.8 & 2790 & 18.7 \\
\hline Primary & 982 & 8.5 & 7843 & 52.5 \\
\hline Secondary and Higher & 8583 & 74.7 & 4316 & 28.9 \\
\hline \multicolumn{5}{|c|}{ Household wealth } \\
\hline Poor & 4176 & 36.3 & 7562 & 50.6 \\
\hline Middle & 2346 & 20.4 & 2628 & 17.6 \\
\hline Rich & 4973 & 43.3 & 4759 & 31.8 \\
\hline \multicolumn{5}{|c|}{ Occupation } \\
\hline Professional & 1369 & 11.9 & 1199 & 16.8 \\
\hline Not working & 9962 & 86.7 & 2441 & 34.2 \\
\hline Agric. Self employed & 72 & 0.6 & 1791 & 25.1 \\
\hline Manual & 92 & 0.8 & 1710 & 23.9 \\
\hline \multicolumn{5}{|c|}{ Maternal age } \\
\hline $15-24$ & 2700 & 23.5 & 4322 & 28.9 \\
\hline $25-34$ & 6676 & 58.1 & 7327 & 49 \\
\hline $35-49$ & 2119 & 18.4 & 3300 & 22.1 \\
\hline \multicolumn{5}{|c|}{ Marital status } \\
\hline Married & 11281 & 98.1 & 12332 & 82.5 \\
\hline Single & 214 & 1.9 & 2617 & 17.5 \\
\hline \multicolumn{5}{|c|}{ ANC visits } \\
\hline None & 1100 & 9.6 & 924 & 6.2 \\
\hline 1 to 2 times & 342 & 3 & 2084 & 13.9 \\
\hline 3 to 4 times & 1126 & 9.8 & 7414 & 49.6 \\
\hline 5 to 8 times & 3078 & 26.8 & 4291 & 28.7 \\
\hline $9+$ times & 5801 & 50.5 & 185 & 1.2 \\
\hline Missing & 48 & 0.4 & 51 & 0.3 \\
\hline \multicolumn{5}{|c|}{ Place of delivery } \\
\hline Public & 3075 & 26.8 & 6895 & 46.1 \\
\hline Private & 7005 & 60.9 & 1853 & 12.4 \\
\hline Home & 1347 & 11.7 & 6013 & 40.2 \\
\hline Other & 67 & 0.6 & 159 & 1.1 \\
\hline Total & 11495 & 100 & 14949 & 100 \\
\hline
\end{tabular}

Source: Generated from 2014 Egypt and Kenya DHS datasets.

Majority of the respondents were from rural areas, although Kenya had a bigger proportion of rural women than Egypt, that is, 58.5 percent (Egypt) and 65.5 percent (Kenya). Two thirds (75\%) of women in Egypt had secondary or higher level of education, compared to Kenya where only a third $(30 \%)$ of the women were in similar level of education. More than half $(52 \%)$ of women in Kenya had attained primary level of education. While $36 \%$ of women in Egypt were classified as poor, majority (51\%) of those from Kenya were in this category. On participation in paid labour, more than 8 out of every 10 women in Egypt were not working while in Kenya, only 3 out of every 10 women were in this category (Table 1).

In both countries, most respondents were aged25-34 Egypt (58\%) and Kenya (49\%), and married - Egypt (98\%) and Kenya $(82 \%)$. In terms of health services seeking behaviour, in Egypt, 77 percent of the women reported having attended antenatal care visits at least 5 times compared to their counterparts in Kenya where only 30 percent did. In Egypt, 88 percent of the respondents reported having delivered in a health facility, with the private hospital being the most preferred at 61 percent. In Kenya, 58.5 percent of the respondents had delivered in a health facility and public facilities were preferred at 46 percent. There were less home deliveries reported in Egypt (11.8\%) compared to Kenya (40.2\%) (Table 2).

As seen in Fig. 1, there were more women (53.5\%) who delivered their last baby via caesarean section in Egypt than in Kenya (7.8\%).

\section{Birth Mode: Egypt and Kenya, 2014 (percent)}

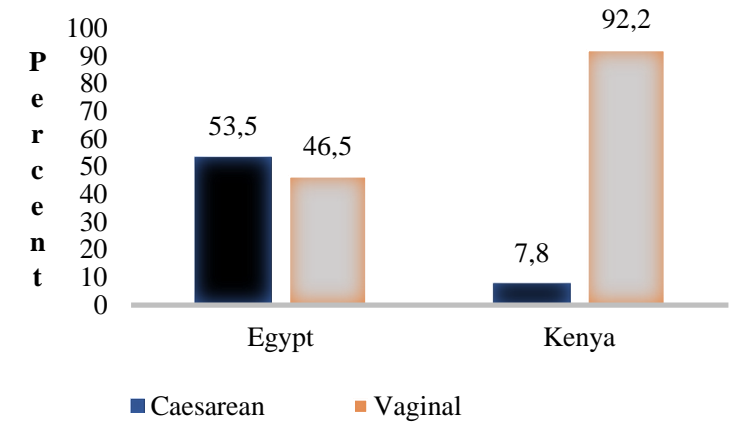

Fig. 1. Mode of childbirth, Egypt versus Kenya (percent). Source: Generated from DHS 2014 data for Egypt and Kenya.

\section{Differentials in the Choice Method of Childbirth Delivery in Egypt and Kenya}

Table 3 gives differentials in type of childbirth delivery comparing Egypt and Kenya given the socio-economic and maternal variables of the study. In Egypt, more than half $(53.2 \%)$ of rural women, 80.8 percent of those with at least secondary level of education, those from wealthy households (51.8\%) and 86.7 percent of those not engaged in labour opted for caesarean section delivery. On the other hand, in Kenya, more women from the urban residence $(53.7 \%)$, those with secondary or higher level of education $(50.9 \%)$ and 57.6 percent of those from wealthy households had a caesarean section delivery. In both countries, the increase in level of education and household wealth were directly related to increase in likelihood of opting for caesarean section delivery (Table 3 ). In addition, married women and those aged 25-34 in both countries had a higher chance of delivering by caesarean section. While all variables were significant at $<0.01$ or $<0.05$ level, marital status was not significant in both countries.

\section{Determinants of the Choice Method of Childbirth Delivery in Egypt and Kenya}

This section presents results from the inferential analysis using "last birth was a caesarean" as the dependent variable. In order to determine the most significant socio-economic, maternal and pregnancy-related factors leading to caesarean section deliveries in Egypt and Kenya, binary logistic regression was used. The results showed that the model was significant at less than 0.01 level according to the model chi-square statistic in both countries. Further, the model could correctly predict 68.9 percent of cases in Egypt and 92.6 percent of the cases in Kenya, respectively. 
TABLE 3: DIFFERENTIALS OF THE STUDY VARIABLES BY THE CHOICE METHOD OF CHILDBIRTH DELIVERY (LAST BIRTH) IN EGYPT AND KENYA,

\begin{tabular}{|c|c|c|c|c|c|c|c|c|c|c|c|c|c|}
\hline \multirow[b]{3}{*}{ Variables } & \multicolumn{6}{|c|}{2014 DHS } & \multirow{2}{*}{\multicolumn{7}{|c|}{ not a significant determinant of type of childbirth delivery }} \\
\hline & \multicolumn{3}{|c|}{ EGYPT } & \multicolumn{3}{|c|}{ KENYA } & & & & & & & \\
\hline & $\begin{array}{l}\text { Vagi- } \\
\text { nal } \\
(\%)\end{array}$ & $\begin{array}{l}\text { Caesa- } \\
\text { rean } \\
(\%)\end{array}$ & $\begin{array}{l}\text { Total } \\
(\%)\end{array}$ & $\begin{array}{c}\text { Vagi- } \\
\text { nal } \\
(\%)\end{array}$ & $\begin{array}{l}\text { Caesa- } \\
\text { rean } \\
(\%)\end{array}$ & $\begin{array}{l}\text { Total } \\
(\%)\end{array}$ & \multicolumn{7}{|c|}{$\begin{array}{l}\text { in Kenya, maternal age was, where women aged } 25-34 \text { and } \\
\text { those } 35-49 \text { were more likely to deliver by caesarean } \\
\text { - section than those aged } 15-24 \text {, at odds ratios } 1.335 \text { and }\end{array}$} \\
\hline Place of & \multirow{2}{*}{\multicolumn{3}{|c|}{$\begin{array}{l}\text { Chi-sq } \\
\text { 151.648Sig. }=.000\end{array}$}} & \multicolumn{3}{|c|}{$\begin{array}{l}\text { Chi-sq Value }=204.893 \\
\text { Sig. }=.000\end{array}$} & \multicolumn{7}{|c|}{1.690 respectively. } \\
\hline $\begin{array}{c}\text { residence } \\
\text { Urban }\end{array}$ & & & & 32.9 & $\begin{array}{c}\text { Sig. }=.00 \\
53.7\end{array}$ & 34.6 & \multirow{3}{*}{\multicolumn{7}{|c|}{$\begin{array}{c}\text { TABLE 4: DETERMINANTS OF THE CHOICE METHOD OF CHILDBIRTH } \\
\text { DELIVERY IN KENYA AND EGYPT, } 2014 \text { DHS }\end{array}$}} \\
\hline Rural & 64.6 & 53.2 & 58.5 & 67.1 & 46.3 & 65.4 & & & & & & & \\
\hline \multirow{3}{*}{$\begin{array}{l}\text { Education } \\
\text { attainment }\end{array}$} & \multirow{3}{*}{\multicolumn{3}{|c|}{$\begin{array}{c}\text { Chi-sq Value }=273.194 \\
\text { Sig. }=.000\end{array}$}} & \multirow{3}{*}{\multicolumn{3}{|c|}{$\begin{array}{l}\text { Chi-sq Value }=364.010 \\
\text { Sig. }=.000\end{array}$}} & & & & & & & \\
\hline & & & & & & & \multicolumn{7}{|c|}{\begin{tabular}{ccc}
\multicolumn{3}{c}{ DELIVERY IN KENYA AND EGYPT, 2014 DHS } \\
EGYPT & KENY $t$
\end{tabular}} \\
\hline & & & & & & & Variables & B & Sig. & $\operatorname{Exp}(B)$ & B & Sig. & $\operatorname{Exp}(B)$ \\
\hline No & \multirow[t]{2}{*}{22.2} & 12.1 & \multirow[t]{2}{*}{16.8} & 19.9 & \multirow[t]{2}{*}{4.4} & \multirow[t]{2}{*}{18.7} & & & Place & Residenc & & & \\
\hline $\begin{array}{c}\text { Education } \\
\text { Primary }\end{array}$ & & 71 & & 531 & & & Rural & .050 & .432 & 1.051 & -.094 & .385 & .910 \\
\hline $\begin{array}{l}\text { Primary } \\
\text { Secondary }\end{array}$ & 10.2 & 1.1 & 8.5 & 53.1 & 44.1 & 52.5 & & & & ation & & & \\
\hline \&Higher & 67.6 & 80.8 & 74.7 & 27 & 50.9 & 28.9 & $\begin{array}{l}\text { No Education } \\
\quad \text { (ref) }\end{array}$ & & .205 & & & .181 & \\
\hline $\begin{array}{l}\text { Household } \\
\text { wealth }\end{array}$ & Chi-s & $\begin{array}{l}\text { Value }=50 \\
\text { ig. }=.000\end{array}$ & 325 & Chi- & $\begin{array}{l}\text { Value }= \\
\text { Sig. }=.00\end{array}$ & .509 & $\begin{array}{l}\text { Primary } \\
\text { Secondary \& }\end{array}$ & -.158 & .083 & .854 & .110 & .605 & 1.116 \\
\hline Poor & 46.5 & 27.5 & 36.3 & 52.8 & 25 & 50.6 & $\begin{array}{l}\text { high } \\
\text { hige }\end{array}$ & -.040 & .537 & .960 & .285 & .192 & 1.329 \\
\hline Middle & 20.1 & 20.7 & 20.4 & 17.6 & 17.4 & 17.6 & & & House & Id Wealt & & & \\
\hline Rich & 33.4 & 51.8 & 43.3 & 29.7 & 57.6 & 31.8 & Poor (ref) & & .000 & & & .175 & \\
\hline Occupatio & Chi-s & Value $=2$ & 474 & Chi & Value $=$ & 096 & Middle & .276 & $.000^{*}$ & 1.318 & -.028 & .849 & .972 \\
\hline $\mathbf{n}$ & & ig. $=.000$ & & & Sig. $=.00$ & & Rich & .531 & $.000 *$ & 1.701 & .202 & .126 & 1.224 \\
\hline Professiona & 10.9 & 128 & 11.9 & 161 & 258 & 16 & & & Oc & pation & & & \\
\hline 1 & & & & & & & Professional & & .875 & & & .925 & \\
\hline $\begin{array}{c}\text { Not } \\
\text { working }\end{array}$ & 87.3 & 86.1 & 86.7 & 34.9 & 25.6 & 34.2 & $\begin{array}{c}\text { (ref) } \\
\text { Not working }\end{array}$ & -.015 & .816 & .985 & -.085 & .547 & .919 \\
\hline Agric. Self & 09 & 0.4 & 06 & 253 & 222 & 251 & Agri-self empl & -.037 & .904 & .964 & -.005 & .973 & .995 \\
\hline employed & 0.9 & 0.4 & 0.0 & 25.3 & 22.2 & 25.1 & Manual & -.204 & .407 & .816 & -.019 & .891 & .982 \\
\hline Manual & 0.9 & 0.7 & 0.8 & 23.8 & 26.4 & 24 & & & Mat & nal Age & & & \\
\hline Maternal & Chi- & Value $=7$ & & Chi & Value $=$ & 618 & $15-24$ (ref) & & .417 & & & .001 & \\
\hline age & & ig. $=.030$ & & & Sig. $=.00$ & & $25-34$ & -.062 & .236 & .940 & .289 & $.017 * *$ & 1.335 \\
\hline $15-24$ & 23.1 & 23.9 & 23.5 & 29.3 & 24.1 & 28.9 & $35-49$ & -.014 & .843 & .987 & .525 & $.000^{*}$ & 1.690 \\
\hline $25-34$ & 57.5 & 58.6 & 58.1 & 48.8 & 51.5 & 49 & & & Mar & l Status & & & \\
\hline $35-49$ & 19.5 & 17.5 & 18.4 & 21.9 & 24.4 & 22.1 & Never married/ & & & & & & \\
\hline $\begin{array}{c}\text { Marital } \\
\text { status }\end{array}$ & Chi- & $\begin{array}{l}\text { Value }=3 \\
\text { ig. }=.082\end{array}$ & & & $\begin{array}{l}\text { q Value } \\
\text { Sig.=.13 }\end{array}$ & & $\begin{array}{c}\text { Separ/ Divor } \\
\text { /Wid }\end{array}$ & -.106 & .491 & .899 & .101 & .420 & 1.106 \\
\hline Married & 97.9 & 98.3 & 98.1 & 82.6 & 80.9 & 82.5 & 3-4 (ref) & & $\begin{array}{l}\text { AN } \\
000\end{array}$ & isits & & 012 & \\
\hline Single & 2.1 & 1.7 & 1.9 & 17.4 & 19.1 & 17.5 & $\begin{array}{l}3-4 \text { (IEl) } \\
\text { None }\end{array}$ & -.272 & $.008^{*}$ & .761 & 687 & $\begin{array}{l}.012 \\
.090\end{array}$ & 1988 \\
\hline None & 15.2 & 4.7 & 9.6 & 6.7 & 0.9 & 6.2 & $1-2$ & -.034 & .819 & .967 & $\begin{array}{l}.007 \\
-.120\end{array}$ & .501 & $\begin{array}{l}1.900 \\
.887\end{array}$ \\
\hline ANC visits & Chi-s & Value $=74$ & 370 & Chi- & $\begin{array}{l}\text { Value }= \\
\text { Sig }=00\end{array}$ & .629 & $\begin{array}{l}1-2 \\
5-8\end{array}$ & $\begin{array}{l}-.034 \\
.259\end{array}$ & $.001^{*}$ & 1.296 & .210 & $.040 * *$ & 1.234 \\
\hline 1 to 2 times & & & & & Sig. $=.00$ & & $9+$ & .578 & $.000^{*}$ & 1.783 & .719 & $.014 * *$ & 2.053 \\
\hline 3 to 4 times & $\begin{array}{c}4.3 \\
12.8\end{array}$ & $\begin{array}{l}1.9 \\
7.2\end{array}$ & $\begin{array}{c}3 \\
98\end{array}$ & & & & & & Place & Delivery & & & \\
\hline 5 to 8 times & 28.6 & 25.4 & $\begin{array}{l}9.8 \\
26.9\end{array}$ & $\begin{array}{l}30.2 \\
27.7\end{array}$ & $\begin{array}{l}45.1 \\
42.1\end{array}$ & $\begin{array}{l}49.8 \\
28.8\end{array}$ & Public Health & & .000 & & & .011 & \\
\hline $9+$ times & 39.1 & 60.7 & 50.7 & 1.0 & 4.2 & 1.2 & facility (re & & & & & & \\
\hline Place of & Chi-sc & alue $=21$ & .597 & Chi-s & Value $=1$ & 2.720 & Home & $\begin{array}{c}- \\
20.822\end{array}$ & .985 & .000 & 19.041 & .980 & .000 \\
\hline $\begin{array}{c}\text { delivery } \\
\text { Public }\end{array}$ & 30.8 & $\begin{array}{c}1 \mathrm{~g} .=.000 \\
23.2\end{array}$ & 26.8 & 44.3 & $\begin{array}{c}5 .=.00 \\
68.6\end{array}$ & 46.2 & Private Health & .723 & $.000 *$ & 2.060 & 363 & $.001 *$ & 1.438 \\
\hline Home & 25.2 & 0.0 & 11.7 & 43.7 & 0.0 & 40.3 & & & & & & & \\
\hline Private & 43,5 & 76.1 & 60.9 & 10.8 & 31.4 & 12.4 & Other & .460 & .073 & 1.584 & - & .997 & .000 \\
\hline Other & 0.5 & 0.7 & 0.6 & 1.2 & 0.0 & 1.1 & Constant & -.585 & .013 & .557 & $\begin{array}{l}19.129 \\
-2.606\end{array}$ & .000 & .074 \\
\hline Total & 5340 & 6155 & $\begin{array}{c}1149 \\
5 \\
\end{array}$ & 13778 & 1161 & 14939 & $0<0.01 * * *$ & 05. & & 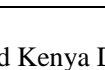 & & & \\
\hline
\end{tabular}

Source: Generated from 2014 Egypt and Kenya DHS datasets.

Table 4 presents the socio-economic, maternal and pregnancy-related determinants of caesarean section deliveries in Egypt and Kenya as per the 2014 demographic and health surveys conducted in both countries. Place of residence, educational attainment of the mother, occupation of the mother, and a mother's marital status were not statistically related to the choice method of childbirth delivery in either of the countries.

Household wealth was a very significant determinant of type of childbirth delivery. In Egypt, women from the middle and rich households were 1.318 and 1.701 times more likely to deliver by caesarean section compared with those from poor households. Although wealth status was not a significant determinant of type of childbirth delivery in Kenya, maternal age was, where women aged 25-34 and section than those aged $15-24$, at odds ratios 1.335 and 1.690 respectively.

列

Separ/ Divor /

\section{ANC Visit}

.000

$\begin{array}{lllll}.000 * & 1.783 & .719 & .014 * * & 2.053\end{array}$

Place of Delivery

Antenatal care is an important service in maternal and child health. The number of visits has a bearing on pregnancy outcomes. Women who fail to access antenatal care services risk having negative pregnancy outcomes and complications during the process of childbirth delivery. The World Health Organisation (WHO) had earlier recommended at least four visits although the current recommendation is eight visits. Women who failed to access antenatal care services were less likely to deliver by caesarean section 0.761) compared with those who had 3-4 antenatal care visits were more likely to deliver by visits in Egypt. Women who made 5-8 and at least 9 
caesarean section (1.296 and 1.783 times, respectively) compared with those who made 3-4 visits. In Kenya, women who had 5-8 visits and those with 9+ visits were 1.234 and 2.053 times likely to undergo caesarean section compared with those who had 3-4 visits.

Place of delivery was a very significant determinant of caesarean section delivery in both Egypt and Kenya. Women who delivered in private facilities were twice likely in Egypt and 1.438 times in Kenya to delivery by caesarean section compared to those delivering in public health facilities.

\section{DISCUSSION}

In identifying the factors that determine the choice method of childbirth delivery among women of childbearing ages in Kenya and Egypt, this study established that the choice method was centred on household wealth (Egypt), maternal age (Kenya), number of antenatal care visits (both Kenya and Egypt), and place of delivery (both Kenya and Egypt). Socioeconomically, Egyptian women from middle and rich households were 1.3 and 1.7 times as likely to deliver by caesarean section as their colleagues from poor households. This is in agreement with a different study that found mothers from rich households to have higher odds of caesarean section delivery compared to those from middle class households [1]. Rich women have elevated access to financial resources needed to pay for the caesarean section deliveries, and because of their financial muscle, they are likely to seek caesarean section prior to their expected due dates. Because of their economic status in the society, rich women might perceive vaginal delivery as painful, stressful, embarrassing and complicated and thus opt for planned caesarean section delivery in pursuit of protecting their societal image. Again, for HIV positive mothers, caesarean section delivery is preferred to reduce the risk of mother to child HIV infection. In Kenya, poor women are able to access free maternal health services under the Linda Mama Programme (a programme that provides equitable healthcare to women) as long as they are registered under the programme. The programme encourages normal/vaginal deliveries as much as possible but in cases of complications, caesarean deliveries are also covered.

Considering maternal age, the likelihood of delivering by caesarean section significantly increased from young mothers to old mothers (from 1.0 to 1.3 to 1.8 for $15-24,25-$ 34 and 35-49 maternal ages) in Kenya. These findings are consistent with existing literature reporting a positive significant association between advanced maternal age and caesarean section delivery [5], [7], [20], [21]. Advanced maternal age at childbirth is related to increased prepregnancy morbidity and associated risk factors that may contribute to an increased risk of caesarean section. A study pointed out that increased maternal age implies a deterioration of physiological functions including the genital tract, the uterine musculature, and the hormonal system [3], all of which necessitate caesarean section childbirth delivery. A Ghanaian study mentioned that older women perceived caesarean section as a safe delivery option to protect their foetus after a long period of conception difficulty, and the fear of delivery pains and losing a baby [5]. Contrarily, one would expect young mothers to deliver by caesarean section because of probably underdeveloped pelvis, anticipated economic challenges and challenges related to first births. Yet studies have reported that young mothers do not opt for caesarean section delivery because of uneasiness, fear associated with caesarean section, the risk of repeated caesarean section births, and the complications associated with more than three repeated caesarean section deliveries [8], [11], [24].

To emphasize the role of pregnancy-related variables in determining the choice method of childbirth delivery, the study found both antenatal care visits and place of delivery to be significantly related to how a mother chooses to deliver her baby both in Kenya and Egypt. In both countries, the likelihood of delivering by caesarean section was directly proportional to the number of antenatal care visits done by the mother whereas childbirth delivery in a private health facility was more associated with caesarean section than those in a public health facility. Probably, the more likelihood of caesarean section delivery with increasing number of antenatal care visits might be as a result of women sensing and/or suspecting maternal and childbirth complications thus opting to attend as many antenatal care visits as possible and such fear translating to caesarean section choice as a childbirth delivery method. It exists in minds of people that private health facilities push for caesarean section deliveries for commercial reasons, and true it is that childbirth delivery by caesarean section is monetarily expensive in private than public health facilities. The caesarean section monetary interest again generally limits childbirth deliveries in private health facilities to the economically stable households thus the association between rich women and childbirth delivery by caesarean section.

The study enjoyed the strength of using data collected the same year and in countries ranked at the same economic status, that is, low mid-income economic status according to the June 2019 World Bank ranking. However, it suffered a number of setbacks, including recall bias, being a crosssectional study design, and some missing variables as can be seen in Table 2, which, suppose they were not missing, the authors could not authoritatively say that the results would have been the same. On recall bias, reproductive events are of significance to women and evidence of accurate recall has been reported [12]. The use of the last birth in the five year period prior to the study greatly minimised recall bias.

\section{CONCLUSION AND RECOMMENDATIONS}

The study established that more than half of Egyptian women delivered their children by caesarean section with only 7.8 percent of Kenyan women following suit. The patterns of caesarean section deliveries were similar for place of residence, maternal age and marital status. Whether a mother delivers her baby by vaginal or caesarean section is determined by household wealth (Egypt), maternal age (Kenya), number of antenatal care visits (both Kenya and Egypt), and place of delivery (both Kenya and Egypt). There was no statistical association between choice method 
of childbirth delivery and place of residence, educational attainment, maternal occupation, and marital status in either of the study countries. Similar trends in odds ratios were observed for caesarean deliveries based on the at least 5 antenatal care visits and delivery in private health facility as compared to 3-4 antenatal care visits and delivery in public health facility.

With World Health Organisation recommending 10-15 percent as the ideal rate for caesarean section deliveries, there is need to seek proper understanding of the reasons behind the high proportion of caesarean section deliveries in Egypt and create policy interventions that promote informed choice to reduce the unnecessary caesarean section deliveries. The authors further recommend research on how antenatal care visits and place of delivery jointly relate to the choice method of childbirth delivery. Given that co-morbidities are not evenly spread across women ages, there is need to seek the causes of the strong association between advanced maternal ages and the risk of caesarean section deliveries.

\section{ACKNOWLEDGEMENT}

We take this opportunity to thank Measure DHS for allowing us to use the datasets from the 2014 Demographic and Health Surveys conducted in Egypt and Kenya.

\section{REFERENCES}

[1] M. O. Arunda, A. Agardh \& B. O. Asamoah. (2020). Caesarean delivery and associated socioeconomic factors and neonatal survival outcome in Kenya and Tanzania: analysis of national survey data. Journal of Global Health Action, Volume 13(1). DOI: $10.1080 / 16549716.2020 .17$

[2] A. Belay \& E. Sendo. (2016). Factors determining choice of delivery place among women of child bearing age in Dega Damot District, North West of Ethiopia: a community based cross-sectional study. BMC Pregnancy and Childbirth, 16(1). 229.

[3] W. Cohen. (2014). Does maternal age affect pregnancy outcome? BJOG; 121:252-254. PubMed| Google Scholar.

[4] CSA (Ethiopia) and ICF International. Ethiopia demographic and health survey 2011: Addis Ababa. Ethiopia and Calverton 2012.

[5] E. Dankwah, S. Kirychuk, W. Zeng, C. Feng \& M. Farag. (2019). Socioeconomic inequalities in the use of caesarean section delivery in Ghana: a cross-sectional study using nationally representative data. International Journal for Equity in health, 18:162.

[6] R. A. Fisher. (1948). Statistical methods for research workers, $10^{\text {th }}$ ed. Edindurg: Oliver and Boyd.

[7] L. Herstad, K. Klungsoyr, R. Skjaerven, et al. (2015). Maternal age and emergency operative deliveries at term: a population-based registry study among low risk primiparous women. BJOG; 122:16421651. PubMed| Google Scholar.

[8] E. Hyginus, N. Eric, I. Lawrence\&N. Sylvester. (2012). Morbidity and mortality following high order caesarean section in a developing country. J Pak Med Assoc. 62: 1016-1019.

[9] S. Juma, V. Nyambati, M. Karama, J. Githuku \& Z. Gura. (2015) Factors associated with caesarean sections among mothers delivering at Mama Lucy Kibaki Hospital, Nairobi, Kenya between January and March 2015: a case-control study. Pan African medical Journal, 2017; 28(1):7.

[10] C. Kingdon, J. Neilson, V. Singleton, G. Gyte, A. Hart, M. Gabby, T. Lavender. (2009). Choice and birth method: mixed-method study of caesarean delivery for maternal request. BJOG; 116:886-895.

[11] H. Litorp, A. Mgaya, H. L. Kidanton, S. Johnsdotter\&B. Essen. (2015). What about the mother? Women's and care givers' perspectives on caesarean births in a low-resource setting with rising caesarean section rates. Midwifery. 31: 713-720.

[12] K. McCarthy, A. Blanc, C. Warren, et al. (2016). Can surveys of women accurately track indicators of maternal and newborn care? A validity and reliability study in Kenya. J Glob Health, 6(2):2.
[13] J. Milne, A. Gafni, D. Lu, S. Wood, R. Sauve \& S. Ross. (2009) Developing and pre-testing a decision board to facilitate informed choice about delivery approach in uncomplicated pregnancy. BMC Pregnancy and Childbirth, 9:50.

[14] M. A. Moffat, J. S. Bell, M. A. Porter, S. Lawton, V. Hundley, P. Danielian \& S. Bhattacharya. (2007). Decision making about mode of delivery among pregnant women who have previously had a caesarean section: a qualitative study. BJOG; 114: 86-93.

[15] I. Mylonas \& K. Friese. (2015). Indications for and risks of elective caesarean section. DeutschesArzteblatt International; 112(29-30):489. PubMed| Google Scholar.

[16] C. D. Naylor, M. Sermer, E. Chen \& K. Sykora. (1996). Caesarean delivery in relation to birth weight and gestational glucose tolerance: a pathophysiology or practice style? Toronto TrihospitalGestaional Diabetes Investigators. JAMA;275(15):1165-1170. PubMed| Google Scholar.

[17] E. Oberg. (August 2020). Child birth delivery methods and types. Medically reviewed on 8/18/2020

[18] G. Omedi \& V. Amwoliza. (2015). Factors associated with low birth weights in Kenya. Research on Humanities and Social Sciences, Vol. 5 (22). Google Scholar.

[19] M. Regan, K. G. McElroy \&K. Moore. Choice? Factors that influence women's decision making for childbirth. The journal for perinatal Education, 22(3), 171-180.

[20] M. K. Richards, M. R. Flanagan, A. J. Littman, A. K. Burke \& L. S Callegari. (2016). Primary caesarean section and adverse delivery outcomes among women of very advanced maternal age. J Perinatol; 36: 272-277. PubMed| Google Scholar.

[21] E. Rydahl, E. Declercq, M. Juhl \& R. D. Maimburg. (2019). Caesarean section on a rise - does advanced maternal age explain the increase? A population register-based study. PLoS One; 14(1): $\mathrm{e} 0210655$.

[22] M. R. Spiegel, "Schaum's outline of theory and problems of probability and statistics". New York: McGraw-Hill, 1992, pp. 116117.

[23] A. S. Teferra, F. M. Alemu \& S. M. Woldeyohannes. (2012). Institutional delivery service utilization and associated factors among women who gave birth in the last 12 months in Sekela District, North-West of Ethiopia: a community-based cross-sectional study. BMC Pregnancy and Childbirth, 12(1), 74.

[24] N. U. Ugwu \& B. de Kok. (2015). Socio-cultural factors, gender roles and religious ideologies contributing to caesarean section refusal in Nigeria. Reproductive Health; 12:70.

[25] WHO recommendations non-clinical interventions to reduce unnecessary caesarean sections ISBN 978-92-4-155033-8, Avenue Appia 20, CH-1211 Geneva 27 Switzerland.

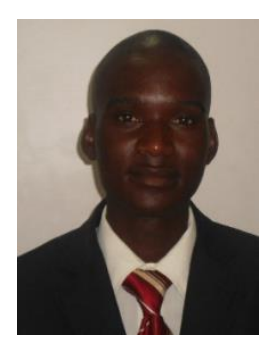

Omedi Gilbert is a $\mathrm{PhD}$ in Geography student at Maseno University, Kenya. He holds a Master Degree in Population Studies (2011) and Bachelor of Education Degree in Mathematics and Geography (2008) both from the University of Nairobi, Kenya.

He is currently a part-time lecturer in Geography at Kaimosi Friends University College and an Associate Lecturer in Geography at Mount Kenya University. He also serves as the Director of Studies at Friends School Senende where he teaches Mathematics and Geography. Previously, he worked as a part-time lecturer in Geography at the University of Nairobi. He has widely published in Population Studies and Demography, with ten peer-reviewed journal publications in his name, participated in seminars and conferences as a paper presenter, rapporteur and an active attendant.

Mr. Omedi is a member of the Population Association of Kenya and has received a number of awards, beginning with a full scholarship by the University of Nairobi to pursue his Masters Degree and other county-level and school-level awards in his high school teaching career.

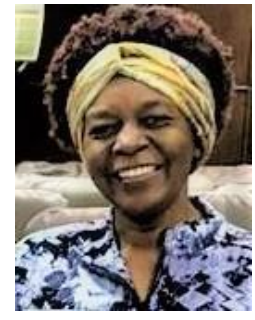

Margaret Mwaila holds a Master of Arts Degree in Population Studies (2011) from the University of Nairobi and a post-graduate Diploma in Population Studies and Sustainable Development (2020) from the Cairo Demographic Centre in Egypt. Her undergraduate study was in Journalism and Media where she majored in Development Communication at the University of Nairobi, Kenya.

She has published one article in a journal. She is a 
Senior Population Programmes Officer in the National Council for Population and Development, a state agency in the State Department for Planning in Kenya. She is proficient in data analysis, both qualitative and quantitative research methodologies and has inherent capability in development communication.

Miss Mwaila is a member of Population Association of Kenya and IUSSP/UAPS - International Union for the Scientific Study of Population/Union for African Population Studies.

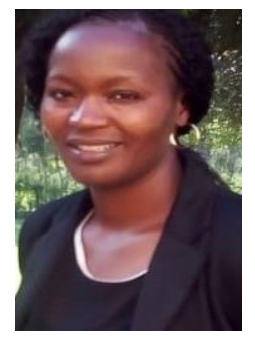

Wanja Sarafina holds a Master of Science Degree in Population Studies (2011), University of Nairobi, Kenya and Bachelor of Science degree in Applied Statistics (2006), Maseno University Kisumu, Kenya.

She is currently the Monitoring Evaluation manager at Infotrak Research and Consulting Limited, Nairobi Kenya. In the past she has worked in various research agencies in Kenya including ETC Consulting Limited, Right Track Africa Ltd, Consumer Insight Ltd and Kantar TNS Ltd. Miss Wanja is a consultant specialized in Monitoring \& Evaluation, Social \& Marketing Research, and Gender mainstreaming issues. She is versed in qualitative and quantitative research methods.

Miss Wanja is a member of the Population Association of Kenya (PAK), Evaluation Society of Kenya (ESK), Marketing and Social Research Association (MSRA). 